\title{
Factors Affecting Use of the Female Condom Among Sexually Active Women in Chongwe District: A Case of Chongwe and Kanakantapa Wards
}

\author{
by \\ Vizevize Zulu
}

\section{ABSTRACT}

The purpose of this study is to investigate and bring out the factors that affect use of the female condom among sexually active women in Chongwe District. The female condom even though widely publicised still remains the least used method of contraception. Based on the 2007 Demographic and Health Survey Statistics, in Zambia alone, use only counts for an alarming 2 per cent of the total women population (Demographic \& Health Survey 2007). This highlights the fact that use among women is very low and this article investigates why use is low.

The study establishes what factors affect use and the study takes place in Chongwe District which provides a fair and general representation of the country's population. Both qualitative and quantitative approaches were used for the present study.

A Descriptive case study method was employed in the study. This method was used because it looks at individuals, groups, institutions, methods and materials in order to describe, compare, contrast, classify, analyse and interpret the entities and the events that constitute their various fields of enquiry. A sample of 250 Chongwe residents both male and female was selected from both Chongwe and Kanakantapa Wards. A Cluster sampling method was employed to select the two Wards Chongwe and Kanakantapa. A list was obtained from organisations (markets, schools, hospitals, council and police) and a sampling frame created. Simple random technique was used to select the total sample of 250 residents.

Questionnaires and interviews were used to collect the data. This method is appropriate and used because it enables the researcher avoid biases in collecting data and to have a full picture of what is really happening concerning the activities surrounding the use of the female condom.

The results show that attitudes, perceived barriers, knowledge and male partner influence all have an effect on female condom use. It was also found that attitudes towards female condom use were very poor in Chongwe district. The majority (46.7\%) were not interested in the female condom at all with only $(20 \%)$ showing interest and (33.3\%) not sure whether or not they liked it or accepted it. The response on knowledge on the other hand was very positive with 70 per cent claiming to have knowledge of the female condom and only 30 per cent having no idea at all. This result proves that knowledge of the female condom still remains high. 
The Demographic and Health Survey states that knowledge is at 65.8 per cent for women and 65.6 per cent for men (Zambia Demographic and Health Survey 2007). Barriers such as price of the commodity, scarcity, victimisation proved to negatively affect female condom use in the district. Forty-five per cent said the commodity was scarce with 10 per cent saying it was expensive. Forty per cent said they were victimised by their male partners with five per cent claiming they were victimised by their fellow females. Male partners influence towards the use of the female condom was also found to have an effect on female condom use. While 77.8 per cent of the female respondents said their male partners refused to discuss use of the female condom and 22.2 per cent had their male partners agree to discuss use of the female condom. Female condom use in Zambia is a matter that still requires stakeholders' involvement.

Workshops and awareness activities must be increased so as to cover all areas including the remotest of places. Distribution of the female condom has to be increased worldwide for it to compete with the already established male condom. Only then can the female condom compete neck to neck with the male condom. Sensitisation campaigns too would play a major role in teaching male folk that the female condom can protect both male and female. Counselling helps overcome women's initial difficulties in using the device. Directing promotional campaigns to men and providing women with negotiation skills are important to overcome men's resistance to use of condoms. Over time, the use of the female condom has concentrated among a subset of women or couples with high motivation to use it; and since the female condom is a relatively new method, initial interest and demand has to be generated (WHO, 1997). This fight needs the input and influence of churches whose involvement could be very effective.

\section{INTRODUCTION}

In 1994, delegates at the International Conference on Population and Development renewed their commitment to the reproductive health needs of women. Adopted by consensus, the conference's programme of action stated that: women have the right to be informed and have access to safe, effective, affordable and acceptable methods of their choice for the regulation of fertility (UN, 1994). This situation makes it necessary to increase measures of prevention which target women, favouring empowerment and providing innovative preventive tools. The female condom is a relatively new device which allows women to choose a barrier method of protection against both unwanted pregnancies and STDs (sexually transmitted diseases) transmission, therefore constituting a valid alternative to the male condom. The female condom was made available in Europe for the first time in 1992, in Great Britain, and has also been approved by the Food and Drug Administration (FDA) for distribution in the United States (Sanita, 2007). The female condom carries various brand names in different countries such as Reality, Femidom, Dominique, Femy, Myfemy and Protective. In Zambia it is called Care and is largely distributed by the Society for Family Health (Society for Family Health, 2009). 
In 2005 only fourteen million female condoms were distributed worldwide, compared to six to nine billion male condoms. One problem in achieving widespread distribution in national programmes has been its cost. In an effort to address the problem of cost, the Female Health Company has developed a second generation female condom (FC2). This new version has similar physical characteristics to the original female condom but is made of synthetic nitrile which utilises a more efficient manufacturing process, particularly at higher volumes (Sanita, 2007).

The female condom has received a lot of support in the past and still continues to do so. The World Health Organisation (WHO) and United Nations AIDS (UNAIDS) are encouraging wider use and access to the female condom as a method of prevention for both unwanted pregnancies and sexually transmitted infections (STIs). The Ministry of Health and non-governmental organisations such as the Society for Family Health and Planned Parenthood Association of Zambia market female condoms as part of their HIV and AIDS prevention and family planning programmes. It provides 94 per cent reliable protection against unwanted pregnancies and HIV and AIDS (Reproductive Health Report MoH, 2007).

Women need to be empowered sexually because most of the reported cases of STIs and HIV and AIDS in women, the principle mode of transmission is through heterosexual sex (Family Planning Handbook, 1997). In most sexual relationships women are placed at a disadvantage as they fail to get their partners to use female condoms and must yield to their control. The female condom is hoping to change the trend as women will be empowered and will be more assertive on self-protection against sure death. The benefits of expanding female condom use could be very great. Wider use of the female condom in developing countries depends on the commitment of governments and other major donors. To achieve its full potential, much greater efforts need to be made worldwide to promote the female condom to make it more accessible and acceptable (PATH, 2006).

\section{STATEMENT OF THE PROBLEM}

The female condom even though widely publicised still remains the least used method of contraception. Based on the 2010 Demographic and Health Survey Statistics, in Zambia alone, use only counts for two per cent of the total women population. This is a very alarming figure. What this means is that female condoms are not being widely utilised in the country. Questions are asked as to why the use of the female condom is low and answers have to be provided. This is the reason this study was undertaken. The situation in Zambia is that unplanned pregnancies, abortions and sexually transmitted infections are on the increase.

A few studies have been carried out on the female condom mainly to determine its acceptability and effectiveness in some parts of the world. Two acceptability studies were conducted in 1996 by Timyan et al., 1996 and Musaba et al., 1996. However, studies on female condom use have been quite minimal with only one notable study that was carried out in Lusaka District (N'gambi, 2001). The findings were not a 
complete representation of the entire Lusaka province. Chongwe, Kafue and Luangwa being the other districts that were not included in the study. This inevitable created a gap in the study as only one district was represented in Lusaka. It would therefore be of great importance to establish the levels of female condom use in Chongwe district.

\section{Research Questions}

1. What is the male partner influence towards the use of the female condom?

2. What are the attitudes of sexually active women towards use of female condoms?

3. What perceived barriers affect female condom use among sexually active women?

4. What are the levels of knowledge on the female condom?

\section{REVIEW OF LITERATURE}

\section{History of the Female Condom}

It is believed that condoms have been used as prophylactics to prevent sexually transmitted infections (STIs) for at least 400 years and as a contraceptive for at least 250 years (Population Reference Bureau, 2011). The first written description of a condom appeared in the year 1564 by an Italian Anatomist, Fallopo who claimed that Uren sheath worn over the penis during sexual intercourse would prevent the spread of diseases. Thus, the history of condoms shows that the use of barrier methods such as covering the penis to protect against disease dates back as far as $1350 \mathrm{BC}$ and for pregnancy prevention as far back as the 16th century AD. Since the 1930s, male condoms have been available as a dual method, but in most parts of the world they have never been widely used (Lewis, 1998).

Early versions of the female condom were available in the 1920s and 1960s but were rarely used and eventually forgotten. As a result of the outbreak of HIV and AIDs, a wider range female controlled barrier technique was required. This rekindled scientific interest in the method. In 1980, three groups in Europe and the USA began development of new female condom designs comprising, the 'Femidom' (Reality), the 'Bikini condom' and 'Women's Choice'. Of the three, Femidom turned out to be the most advanced to date in terms of development and clinical testing and is the only one to have reached the marketing stage (Pyke, 1997).

The decision to have the condom marketed for pregnancy as well as STIs and HIV and AIDS prevention was made by the Obstetrics/Gynaecological Devices Advisory Panel of the Food and Drug Administration (FDA) in December 1992 and was first officially launched in Switzerland and the United States in the same year. It was then approved for marketing in 1993 (Ruminjo, K. et al., 1996). By August 1996, it had been marketed in thirteen countries including the Republic of Korea, South Africa, Spain, Thailand, the United Kingdom, the USA and Zambia. In Zambia, the female condom was introduced in 1996 and was launched at a Society for Women and AIDS Conference by the Society for Family Health (SFH) in 1997. On 15 October 1997 
the condom was officially launched by the Ministry of Health $(\mathrm{MoH})$ and its partners (Nkhama, et al., 1998).

\section{Studies}

A few studies have been carried out on the female condom mainly to determine its acceptability and effectiveness in some parts of the world. Two acceptability studies were conducted in 1996 by Timyan et al., 1996 and Musaba et al., 1996. However, studies on female condom use have been quite minimal with only one notable study that was done by N'gambi (2001) in Lusaka district. The findings were not a complete representation of the entire Lusaka province because Chongwe, Kafue and Luangwa districts were not included in the study. This inevitable created a gap in the study as only one district was represented in Lusaka. It would therefore be of great importance to establish the levels of female condom use in Chongwe district.

The findings of Chongwe would not in any way conflict with the findings of Lusaka district. Chongwe district has an entirely different social and economic set up as that of Lusaka district. A study on sexual activity and condom use in Zambia was carried out by Sohail Agha in March 1998. The 1996 Lusaka Sexual Behaviour and Condom use Survey gathered data on sexual activity in Lusaka from 806 respondents and multiple regression analysis was performed to identify factors that predicted men's and women's use. The results highlighted that overall 17 per cent of women and 24 per cent of men had used a condom at last sexual intercourse. This study did not highlight the factors that affected condom use. A gap existed. This could have given us an insight as to why condom use was so erratic.

\section{Support for the female condom}

World Health Organisation (WHO) and UNAIDS are encouraging wider access to the female condom as a method of preventing both unwanted pregnancy and sexually transmitted infections. Many governments and non-governmental organisations provide female condoms for free or at subsidised prices as part of the HIV prevention and family planning programmes. The Planned Parenthood Association of Zambia is one such non-governmental organisation distributing female condoms for free. It is not clear though just how many areas around the country have received this support.

\section{Worldwide use and availability}

The availability and distribution has increased significantly in the past few years. In 2009 around twenty-six million female condoms were provided through international and non-governmental sources of funding compared to 10.7 million in 2006 but the global distribution of the female condoms is still far less than that of the male condoms (UNAIDS, 2010). 


\section{Future of the Female Condom}

A number of new female condoms such as PATH's women condoms are currently being developed. The aim of this is to address the common disadvantages of current female condoms on the market. However, these female condoms are still a long way from being available and their future prospects are uncertain. With women and girls accounting for just over half of all people living with HIV worldwide, female HIV prevention initiatives are still desperately needed. The female condom is the only female initiated HIV prevention method presently available and it has the potential to empower women to protect themselves from the risk of HIV infection. Greater efforts need to be made worldwide to make the female condom more affordable, accessible and acceptable (PATH, 2011).

\section{METHODOLOGY}

This section outlines the means that led to the achievement of the main objective of the present study. It includes explanation and justification of the research design, which basically outlines the research approach and the research method. This chapter further explains the methods and sources of data collection, the target population and sample size, the sampling procedure, the data collection instruments used, the method of data analysis, ethical considerations and the limitations encountered during data collection.

\section{Research Approach}

Both qualitative and quantitative approaches were used for the present study in order to overcome the weaknesses of each one of them and take advantage of their strengths.

\section{Research Method}

A descriptive case study research method was used for the present study. Descriptive case study was used because it studies and looks at individuals, groups, institutions, methods and materials in order to describe, compare, contrast, classify, analyse and interpret the entities and the events that constitute their various field of enquiry. It deals with the present.

\section{Population and Sample Size}

With a population of 137471 residents in Chongwe the sample had to be representative. The population included all residents of Chongwe district from which a sample size of 250 residents of Chongwe district were selected. This was more than the required 20 per cent of respondents selected from a given sampling frame. Lists of respondents from the different organisations (markets, schools, hospitals, council and police) were obtained. A sampling frame was then created from the lists. From the sampling frame, simple random technique was then used to select the respondents. 


\section{Sources of Primary Data}

To collect primary data, a field study (survey) was undertaken to identify the respondents. Data from the respondents was then collected by asking them questions related to the subject under investigation. Primary data is empirical data because it is obtained through direct observations and experiences. The importance of utilising primary data in this present study is that it is the most reliable, valid and relevant data to enable the researcher adequately answer the questions the research topic raised.

\section{Sources of Secondary Data}

Secondary data refers to data already available in various documents as recorded in books, magazines, journals and reports among others. Secondary data is collected by conducting a desktop research. The importance of secondary data for the current study is that it enables the researcher to gain access to related recorded literature on the subject matter. The secondary data therefore enhances the understanding of how much has been written on the subject under investigation.

\section{Method of Data Collection}

Both questionnaires and interviews were used as methods of collecting quantitative and qualitative data. This approach of using more than one method is known as multimethod. According to Cohen and Manion, the use of a multi-method approach in data collection eliminates the bias or distortion of the researcher's picture of reality. In other words, a combination of tools of data collection presents the possibility of minimising the limitations of a single method since no single method is considered to be error-proof. Therefore, this method was found to be appropriate because it enabled the researcher to avoid biases in collecting data and have a full picture of what was happening concerning the activities surrounding the use of the female condom (Cohen and Manion, 1980).

\section{Questionnaires}

Some questionnaires were self administered. This technique was employed because the respondents were understood to be literate and conversant with the language used. Other questionnaires were semi-administered in cases were the respondents were not fully literate.

\section{Interviews}

Unstructured interviews were used to collect data. This technique was employed because of the freedom the interviewer has to adapt both to changing situations and a variety of respondents. Such interviews also give the interviewer liberty to ask many questions to get more detailed information than limiting themselves to a set of predetermined questions. 


\section{Data Processing}

The questionnaires were edited thoroughly to eliminate all unusable and contradictory data. After correcting all the errors in the questionnaires that could influence data analysis, a coding scheme was developed. After coding, the master table was created and all the raw data was entered and stored electronically using Statistical Package for Social Sciences software (SPSS).

\section{Data Analysis}

Data analysis refers to examining what has been collected in a survey or experiment and making deductions and inferences. The type of data collected determines the method of presenting and analysing it. In case of the present study, both qualitative and quantitative data was collected and as such qualitative and quantitative data analysis methods were employed.

\section{Analysis of Quantitative Data}

Electronic data processing techniques were used to analyse quantitative data which was collected and edited. This was carried out using SPSS.

\section{Analysis of Qualitative Data}

Theme and content analysis was employed to analyse qualitative data. Using this qualitative analysis technique, the following steps were adhered to by the researcher in the analysis of qualitative data. Firstly, the researcher perused the collected data through interviews and identified information that was relevant to the research questions. Irrelevant information not related to the specific objectives and research questions was separated from relevant information. Secondly, the researcher identified themes from the respondents' description of their experiences. All material relevant to a certain theme was placed together. Thirdly, the direct quotations were used to present the findings. These direct quotations reflect the deep thoughts and feelings of the respondents on what their experiences were concerning the use of the female condom. The relevant information was broken down into key quotations which reflected specific thoughts of the respondent. The quotations were then presented in a narrative form.

\section{PRESENTATION OF QUALITATIVE DATA}

Qualitative data was collected using discussions with the respondents. This added a more in-depth and personal touch to the study. Respondents were able to open up and shared their experiences. It also helped respondents gain some comfort and were able to freely contribute to the study. All respondents had different opinions concerning the use of the female condom. One very common piece of information was that knowledge of the female condom was quite high to most. Below are what some respondents had to say: 
Amake Roda: 'My friends tell me that the female condom is difficult to use'.

Judy:

'The female condom is not as popular as the male condom. This makes it difficult for me to introduce it in my marriage'.

Carol: 'I cannot ask my husband to allow me use it because he would not even listen to me'.

Mai Njovu: 'It is difficult to bare children when you use a female condom'.

Pamela: 'My husband and I do not use any condom. Once a health worker distributed the female condom and was among the first to collect some but not with the intention of using but for curiosity reasons. I ended up making bangles for my wrist'.

Narson: $\quad$ 'I can use a female condom but where do I start from. I'm just not bothered.'

Charles: 'I've heard about it but haven't had the chance to see and use it. People tell me it's not as nice as the male condom'.

Wendy: $\quad$ 'I have used it before and I found it too uncomfortable and long.' It made a lot of noise'.

A general assumption based on the respondents in the discussion, one would conclude that the female condom was not as popular as the male condom for various reasons. The most noticeable reasons; being; too complicated to use; bad side effects; costly, not welcome in marital homes; against church norms; and too old to try. These and many more would qualify as some factors affecting the use the female condom among women in Chongwe. A smaller number showed willingness to use the female condom with others showing willingness to use it in the near future. The female condom still remains unpopular. Stigma surrounding the use of the female condom is very negative. Eighty per cent of the members during the discussion expressed levels of negativeness towards the use of the female condom. Only with continued sensitisation and marketing can a positive gain be seen towards the use of the female condom.

\section{FINDINGS ON THE DEMOGRAPHIC CHARACTERISTICS OF THE SAMPLE}

\section{Chart 1.1: Distributions of Respondents by Sex}

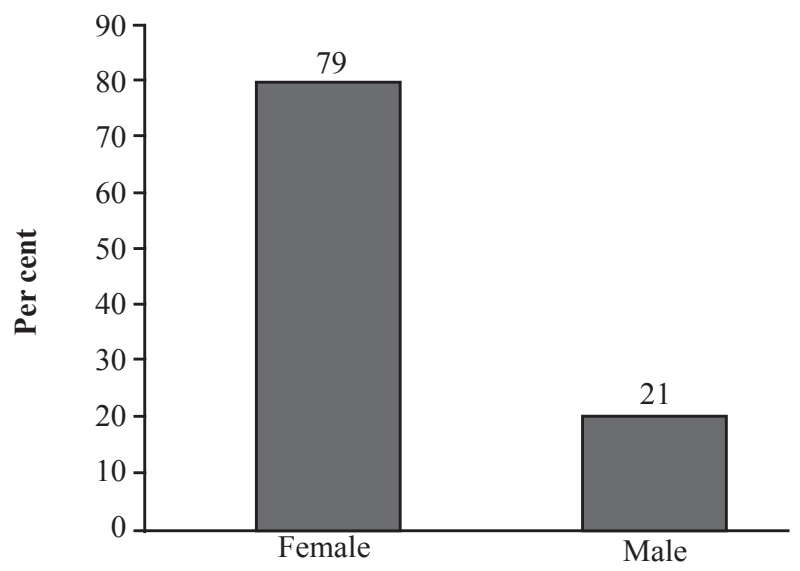


The above bar chart indicates that the majority of the respondents representing 79 per cent $(79 \%)$ were females while the other 29 per cent (29\%) were males.

\section{Chart 1.2: Distributions of Respondents by Age}

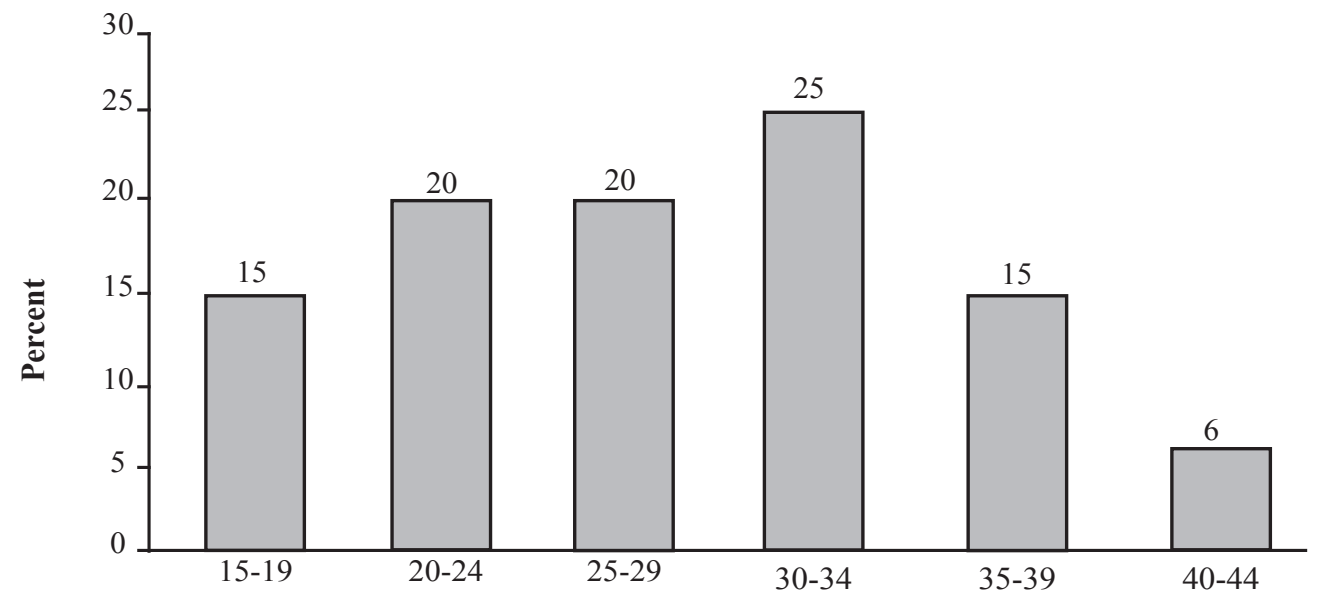

Age Groups

Source: Field Data, 2012

The above bar chart indicates that the majority of the respondents representing 25 per cent $(25 \%)$ were in the age group of thirty to thirty-four while the minority representing 6 per cent $(6 \%)$ belonged to the age group of forty to forty-four. The figure also indicates that 20 per cent $(20 \%)$ of the respondents were in the age group of twenty to twenty-four and twenty-five to twenty-nine.

\section{Chart 1.3: Distributions of Respondents by Religious Affiliation}

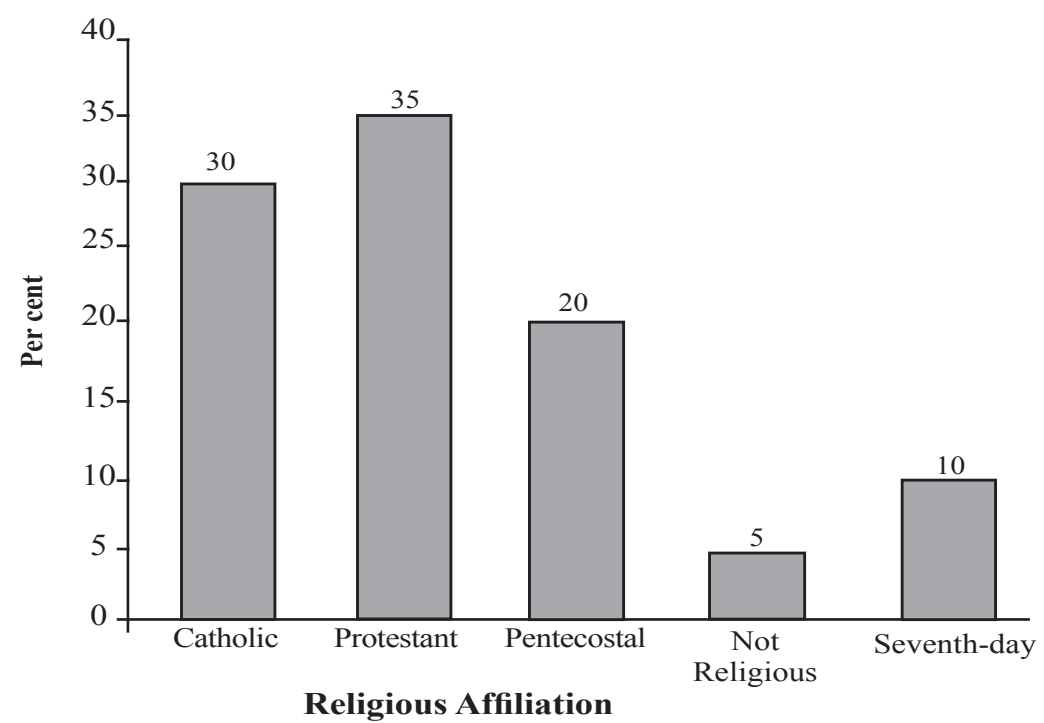


The above bar chart indicates that the majority of the respondents representing 35 per cent (35\%) were Protestants, 30 per cent (30\%) Catholics, 20 per cent $(20 \%)$ Pentecostal and 10 per cent (10\%) belong to Seventh-day Adventists.

\section{Chart 1.4: Distributions of Respondents by Educational Level}

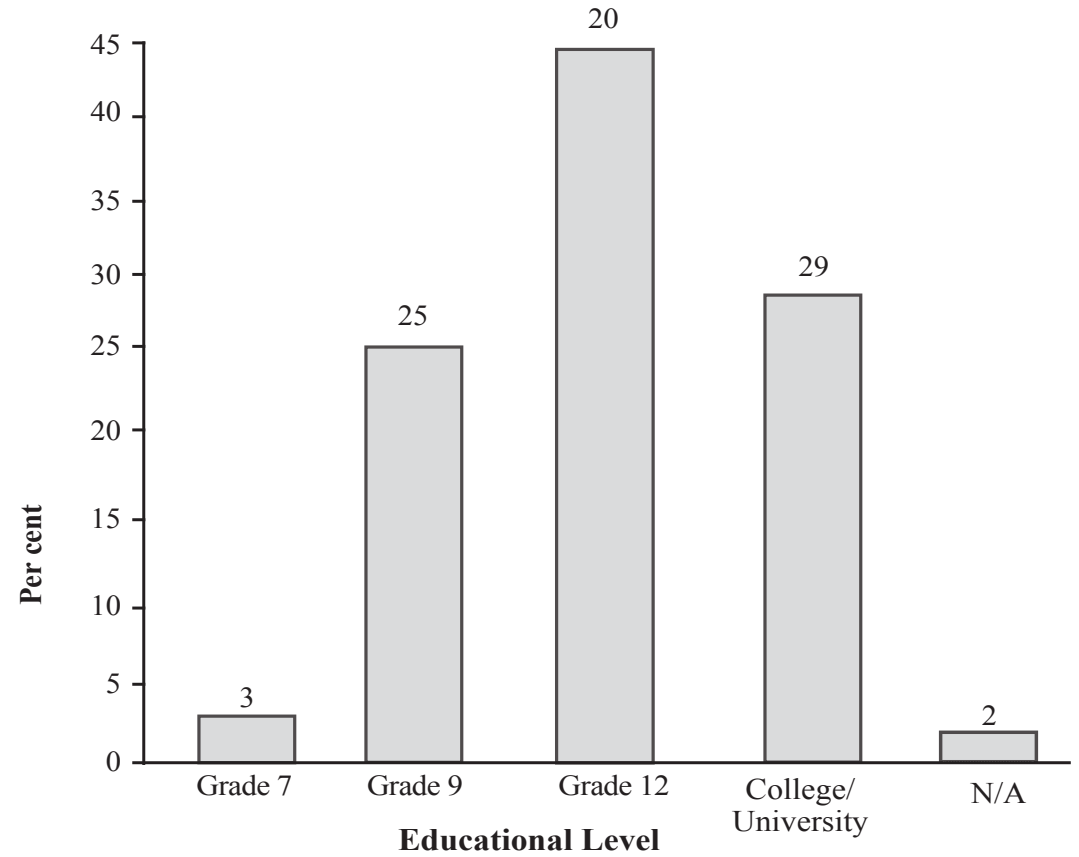

Source: Field Data, 2012

Bar Chart 1.4 shows the distribution of respondents by educational level. The figure indicates that the majority representing 41 per cent (41\%) had attained Grade Twelve qualifications while 29 per cent (29\%) attained College or University qualification. The figure also shows that 25 per cent $(25 \%)$ were educated up to Grade nine and 3 per cent (3\%) up to Grade three.

\section{Chart 1.5: Distributions of Respondents by Educational Level}

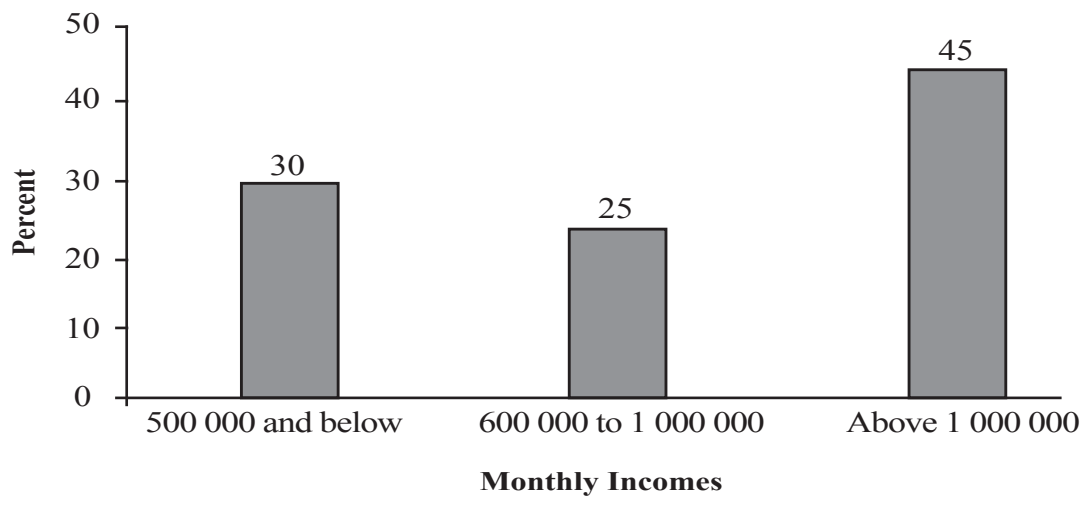


Bar Chart 1.5 indicates that the majority of the respondents representing 45 per cent (45\%) get a monthly income of above one million kwacha (K1 000 000.00). Thirty per cent $(30 \%)$ of the respondents who participated in the survey get below five hundred thousand (K500 000.00). Twenty-five per cent $(25 \%)$ get between six hundred thousand and one million.

\section{Chart 1.6: Distributions of Respondents by Number of Children}

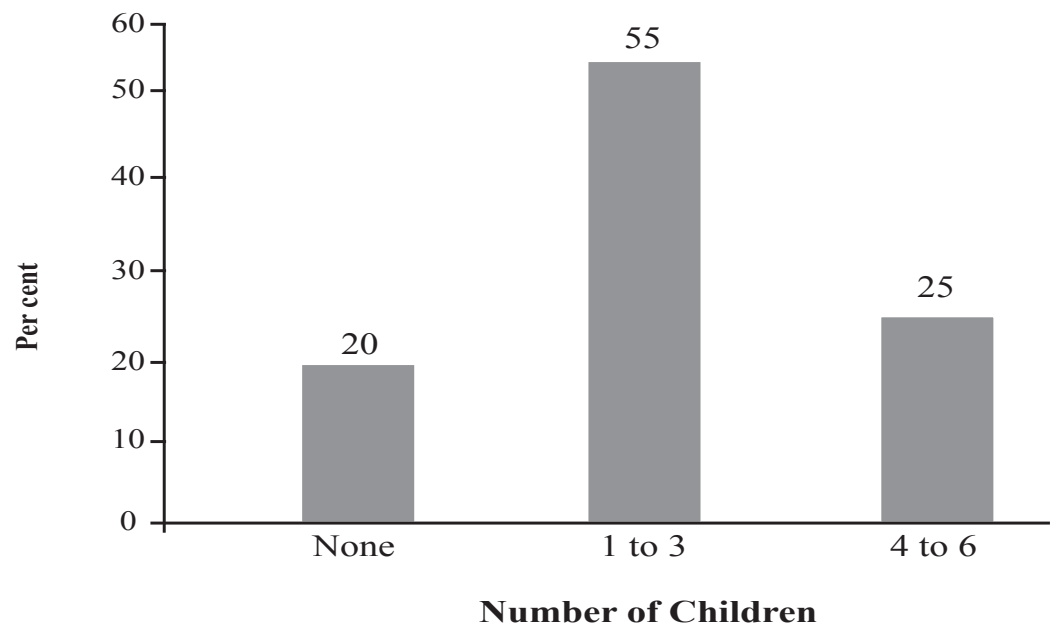

Source: Field Data, 2012

Bar Chart 1.6 shows the distribution of respondents by the number of children (family size). The figure indicates that the majority of the respondents representing 55 per cent (55\%) had one to three children (1 to 3). Twenty-five per cent $(25 \%)$ had four to six children (4 to 6) while twenty per cent (20\%) had none.

\section{PRESENTATION OF QUANTITATIVE DATA}

\section{Chart 2.1: Attitudes Towards Use of the Female Condom}

This chart shows that attitudes are very negative when it comes to female condom use. forty-seven per cent (47\%) of the respondents showed no interest at all in the female condom with 33 per cent (33\%) not sure whether they liked it or not. Only 20 per cent (20\%) said they liked the female condom and were willing to try it. 


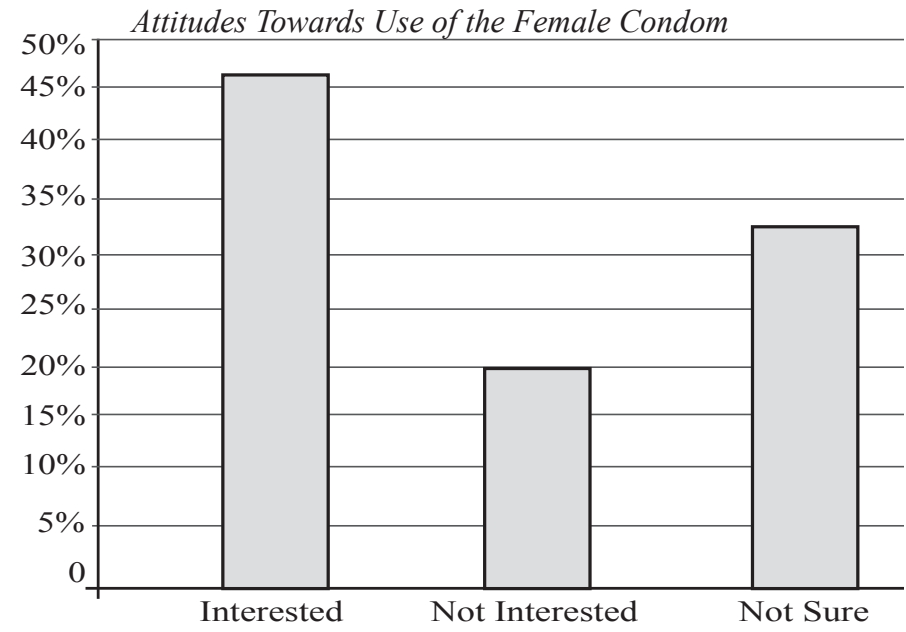

Attitudes towards use of the female condom

Source: Field Data, 2012

\section{Chart 2.2: Knowledge of the Existance of the Female Condom}

The figure shows that the majority of the female respondents showed knowledge towards the female condom. A total of 70 per cent $(70 \%)$ said they knew what the female condom was and were also aware that it was not very popular. Only 30 per cent $(30 \%)$ did not know what the female condom was or were not sure what it was.

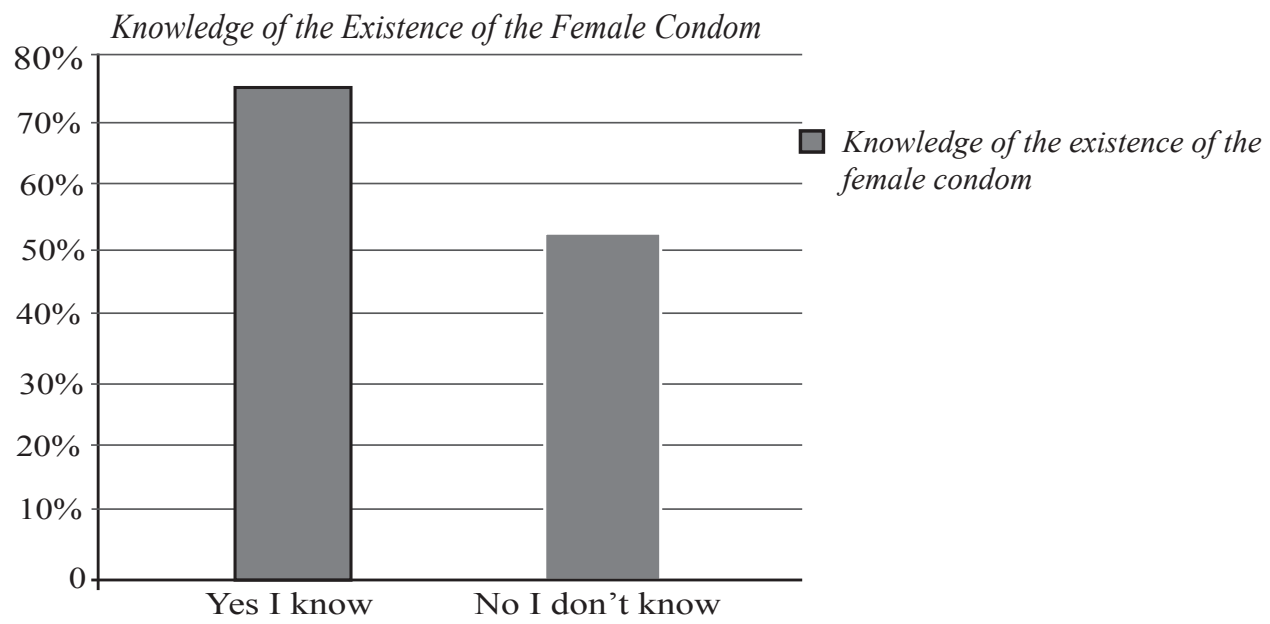

Source: Field Data, 2012

\section{Chart 2.3: Perceived Barriers on Female Condom Use}

The figure shows that scarcity and price are some of the major contributors to poor use of the female condom. Victimisation of females from fellow females is very low at 5 per cent $(5 \%)$ as well as victimisation from the male folk is at 10 per cent $(10 \%)$. Fortyfive per cent of the respondents said they found it difficult to access the female condom with many due to logistical complications. Forty per cent found the commodity a bit too pricy when compared to the price of the male condom. This discouraged many. 


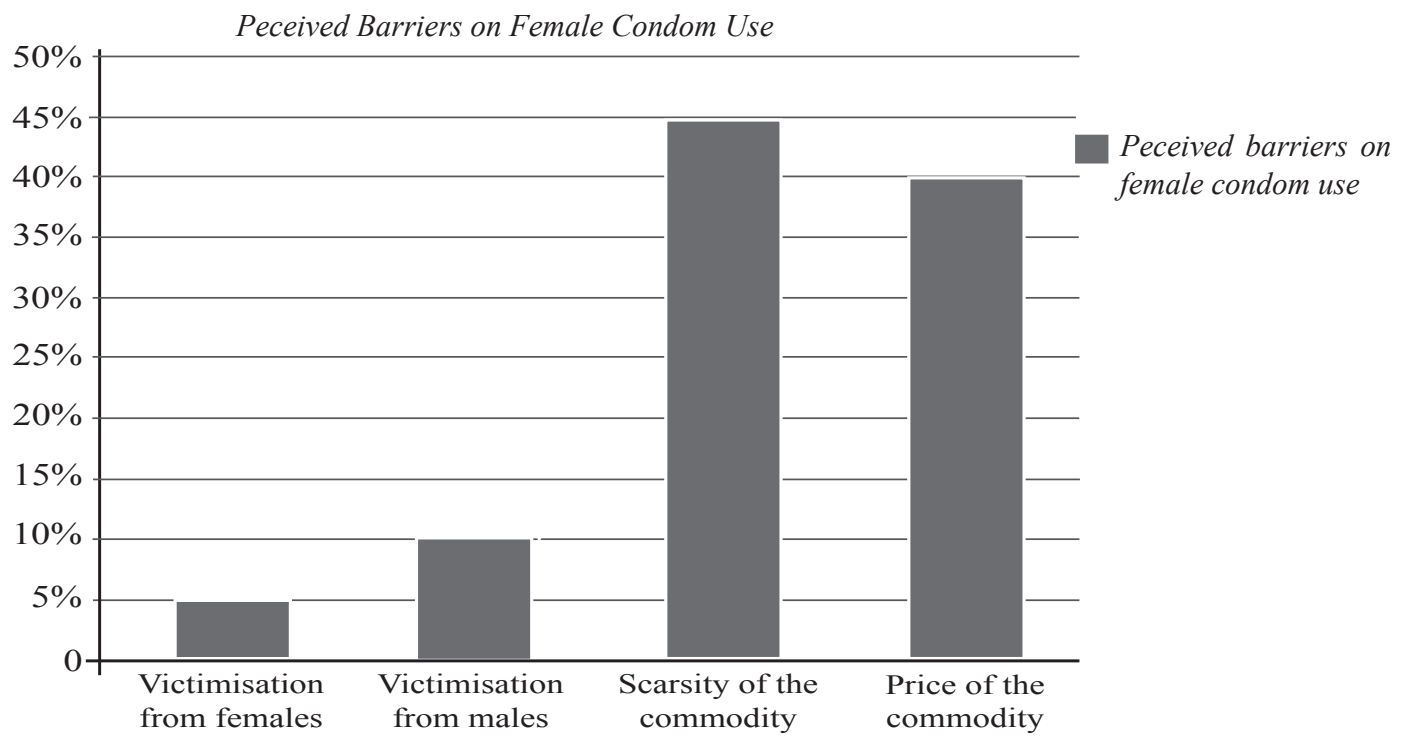

Source: Field Data, 2012

\section{Chart 2.4: Male Partner Influence Towards Use of the Female condom}

The Figure indicates how partner influence can affect condom use. About 77.8 per cent female did not get any help from their male partners when it came down to negotiating condom use. Only 22.2 per cent agreed to discuss female condom use with their wives. This even showed willingness to use the female condom.

Male Partner Influence Towards Use of the Female condom

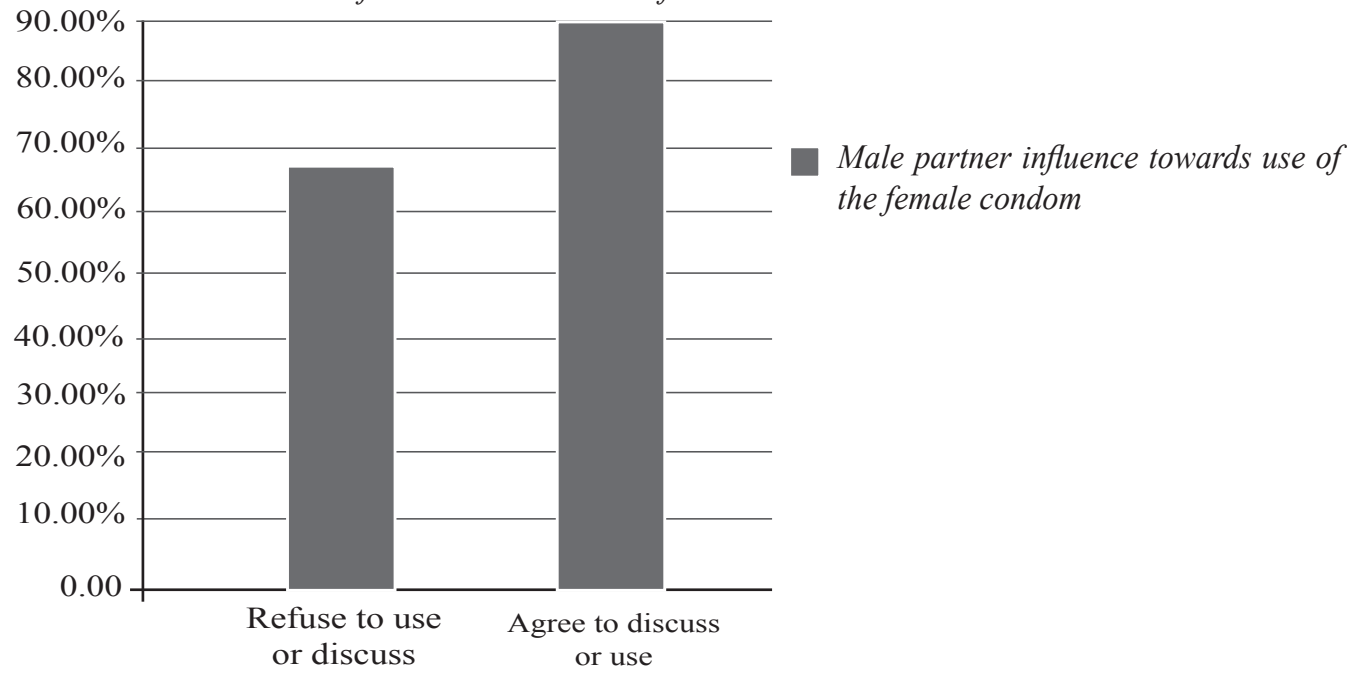




\section{DISCUSSION AND CONCLUSION}

The results show that female condoms are still unpopular among the locals of Chongwe District. Even though knowledge remains high (70\%), attitudes still remain very low. This results in negativity towards the female condom. Attitudes, partner influence and perceived barriers all play a major role in female condom use. The female condom was introduced onto the market much later than the male condom. As a result, people have grown accustomed to the male condom and now trust it more than they can trust the female condom.

The general attitude towards the female condom is bad with many showing curiosity but not interested to use it at all, claiming it was either too complicated to use or it just looked ugly. One of the reasons why the use of the female condom in Chongwe district is low, is because men refuse to discuss condom use with their partners or wives. This is because it is perceived to be an inferior mode of contraception and as a result women do not bother exploring it further. Mrs Alice M. Chembe the Officer in-charge at Planned Parenthood Association of Zambia (PPAZ) clinic maintains that female condom use has not made any gains in terms of the number of people using it. A lot of people are curious more than anything else. Mrs Chembe also highlights the fact that even though female condoms are distributed in certain areas, they doubt if the condoms are ever used.

One recent survey carried out by PPAZ found that the female condoms they had distributed were being boiled by the women in order to extract the steel rings from the condoms to wear them as bracelets. The female condom in this case is more of a souvenir than it is an instrument of protection of unwanted pregnancies and HIV and AIDS. Victimisation no matter how small will affect the female condom use. Some women cannot openly declare they are using the female condom for fear of victimisation from fellow pears.

The introduction of the female condom in some homes is seen as a provocation to culture, spiritual and traditional beliefs. One woman by the name of Betty out-rightly turned down an opportunity to learn about the female condom saying it was a taboo to introduce such into her home let alone convince her husband to consider using the female condom. 'If he is happy with the male condom then so be it'.

In Chongwe district, the majority of women who have heard about the female condoms develop a negative attitude even before they can explore them. This is because it is an open discussion that female condoms are difficult to use, they look ugly, they smell bad, they make a lot of noise, they are very uncomfortable for the man and they can have side effects too. When women hear all these, they do not even bother to try. Dorcas said:

'My cousin got a female condom from the clinic once and tried to experiment by inserting it into her virgina and she developed a serious rush soon after. I can never try it. I'll stick to maximum for maximum protection'.

Things that they hear prevent them from trying. Great distances to the major health centers like Chongwe clinic discourage many. Mr Yasini sees no sense at all in riding his bicycle that great distance to buy a female condom, 'Maximum already does the job, why do we need a female condom?' 
Even though there are some people who look at the female condom as a positive initiative but as long as the majority does not see any reason in it why should so much importance be attached to the female condom its use will always remain low. Female condom use in Zambia is a matter that still requires stakeholders' involvement. Workshops and awareness activities must be increased so as to cover all areas including the remotest of places. Distribution of the female condom has to be increased worldwide for it to compete with the already established male condoms. Only then can the female condom compete neck to neck with the male condom. Sensitisation campaigns too would play a major role in teaching male folk that the female condom can protect both male and female.

\section{REFERENCES}

Cohen, L. and Manion L. (1980), Action Research. London: Harper and Row. Lewis, J. (1998), 'The Female Condom', IPPF Medical Bulletin.

PATH (1995 - 2011), PATH's Woman's Condom.

Planned Parenthood Association of Zambia, Family Planning Handbook (1997). Population Reference Bureau (2010), World Population Data Sheet.

Pyke, M. (1997), Contraceptive Reproductive Health Care. London.

Reproductive Health Report (2007), Ministry of Health.

Ruminjo, J.K. (1996), 'Preliminary Comparison of the Polyurethane Female Condom with Latex Male Condom in Kenya', East African Medical Journal, 73: 2.

Sanita, A. (2007), The Female condom: Knowledge, attitude and willingness to learn, Vol. 43.

Smith, J.B., Nkhama, G. and Trottier, G. (1998), 'Female Condom Reuse in Zambia', Journal of Urban Health, 2001.

Society for Family Health (2009).

UNAIDS (2010), Report on Global Aids Pandemic.

Zambia Demographic and Health Survey (2007). 